\title{
Effects of Aging on the In Vitro Response of Human Lymphocytes to Interleukin-2
}

\author{
Naohiro Yamashita, MD, Hidehiko Suzuki, MD, Muneharu Maruyama, MD, \\ Eiji Sugryama, MD and Saburo Yano, MD
}

\begin{abstract}
Effects of aging on the in vitro responses of human peripheral blood lymphocytes (PBL) to interleukin-2 (IL-2, T-cell growth factor) were studied. Aged PBL showed a significantly lower response to phytohemagglutinin (PHA) than young PBL. On the other hand, proliferative responses to exogenous IL-2 showed by aged PBL were found to be in same extent as those of young PBL. In addition, cultured lymphoid cells propagated in IL-2 (CLC-IL-2) derived from both young and aged PBL showed a strong cy totoxic reactivity against the natural killer (NK) sensitive target K562.
\end{abstract}

Key Words: Interleukin-2 (IL-2), Aging, Natural killer (NK) activity, Mitogenic response

Changes associated with age in immune function in experimental animals and in humans have been described ${ }^{1)}$. It is well established that lymphocytes from subjects over 65 years of age, incorporate less thymidine than those from young subjects when cultured with plant lectin ${ }^{2)}$. Recent studies revealed that mitogen-induced proliferation of murine and human $\mathrm{T}$ lymphocytes in culture is driven by IL-2, T cell growth factor, produced by $\mathrm{T}$ lymphocytes being stimulated with lectins or antigen. Some authors ${ }^{3,4)}$ suggested that the proliferation of lymphocytes may depend upon their capacities to produce IL-2 and their abilities to respond to IL-2.

It was reported that in vitro incubation of human lymphocytes with IL-2 can induce the proliferation to their CLC-IL-2 and CLC-IL-2 thus derived were reported to exhibit a strong cytotoxic reactivity against the tumor cells resistant to lysis of natural killer cells and also against NK-sensitive tumor cells ${ }^{3,5-7)}$.

Little is known for the proliferative ability of aged PBL in the presence of exogenous IL-2 and the cytotoxic reactivities of CLC-IL-2 derived from aged PBL. In the present study, PBL from the young and aged subjects were found to be able to propagate to a large number with IL-2 and CLC-IL-2 thus derived from aged PBL exhibit a strong cytotoxic reactivity against the NKsensitive target cell K562 like young PBL, were reported.

\section{MATERIALS AND METHODS}

\section{Subjects}

Blood was obtained from healthy persons between 21 and 31 years in our laboratory and from those volunteers of ages ranging from 71 to 90 years old. Care was taken to choose the aged persons who were found to be healthy or apparently healthy without those diseases enough to affect their immune system.

Media

PRMI-1640 medium (Nissui Seiyaku Co., Tokyo) supplemented with $10 \%$ heat-inactivated fetal bovine serum (Grand Island Biological Co., Grand Island, N.Y.), $2 \mathrm{mM}$ L-glutamine, penicillin $(100 \mathrm{U} / \mathrm{ml})$, and streptomycin $(100 \mu \mathrm{g} / \mathrm{ml})$ (RPMI/HI-FBS) was used unless otherwise noted.

From the First Department of Internal Medicine, Toyama Medical and Pharmaceutical University, School of Medicine, Toyama.

Received for publication February 17, 1984.

Reprint request to: Naohiro Yamashita, MD. The First Department of Internal Medicine, Toyama Medical and Pharmaceutical University, School of Medicine, 2630, Sugitani, Toyama, 930-01, Japan. 
Click's medium was prepared as described ${ }^{8)}$.

Preparation of PBL

PBL were separated by means of Ficoll-Isopaque density-gradient centrifugation ${ }^{9)}$. Adherent mononuclear cells were removed by incubation in $55 \mathrm{~cm}^{2}$ tissue culture dishes (Falcon 3003, Div. Becton, Dickinson and Co., Cockeysville, MD.) in a $5 \% \mathrm{CO}_{2}$ atmosphere for $1 \mathrm{hr}$.

Preparation of human IL-2

Partially purified human IL-2 was kindly provided by Dr. Yoshikatsu Hirai, Institute of Otuska Pharmaceutical Co., Tokushima, Japan. It was obtained by culturing human spleen cells with PHA as previously described ${ }^{10)}$. Briefly, after $48 \mathrm{hr}$ incubation, PHA-stimulated cells obtained were removed by centrifugation and the supernatants thus obtained were passed through $0.45 \mu \mathrm{m}$ filters to remove cellular debris. The supernatants were then precipitated by sequential ammonium sulfate precipitation, followed by DEAE column chromatography and by gel filtration on an Ultrogel AcA 54 column. Then the active portion obtained was exposed to $\mathrm{pH} 2.0$ to destroy "immunological" interferon (IFN) activity. High concentrations of the purified IL-2 activities were found to be not directly mitogenic to normal mononuclear cells, thus further presence of lectin as judged no longer to occur. Furthermore, significant IFN activity was undetectable in these preparations. Units of IL-2 were determined as the reciprocal of the dilution degree that induce $50 \%$ of the maximal ${ }^{3} \mathrm{H}$-thymidine incorporation ${ }^{11)}$ by the standard IL-2-dependent human cytotoxic $\mathrm{T}$ cell line. $\mathrm{T}$ cell line had been induced by mixed lymphocyte culture reaction between normal human peripheral $\mathrm{T}$ cells and mitomycin C-treated CESS cells and maintained in IL-2 for more than 16 weeks ${ }^{12)}$.

\section{CLC-IL-2}

PBL at $5 \times 10^{5}$ cells $/ \mathrm{ml}$ were cultured with $10 \mu \mathrm{g} / \mathrm{ml} \mathrm{PHA}$ and $5 \mathrm{U} / \mathrm{ml}$ of IL-2 in Click's medium in tissue culture dishes (Falcon 3001). After 2 days of culture, cells were washed, counted in a hemocytometer and subcultured every 3 days at $1 \times 10^{5}$ cells $/ \mathrm{ml}$ in Click's medium containing $5 \mathrm{U} / \mathrm{ml}$ of IL-2. In this study, we used $5 \mathrm{U} / \mathrm{ml}$ of IL-2, at which final concentration was found to be optimal for the proliferation for PBL in the preliminary study using the concentrations of 0.2 to $15 \mathrm{U} / \mathrm{ml}$ of IL-2 for culture (data not shown). On the ninth and fifteenth day of culture, the cells at $1 \times 10^{5}$ cells/well were added to Microtest III culture plates (Falcon 3072) and incubated in the presence of $5 \mathrm{U} / \mathrm{ml}$ of IL-2 for $24 \mathrm{hr}$. The cells thus cultured were pulsed with ${ }^{3} \mathrm{H}$-thymidine $(0.5 \mu \mathrm{Ci} /$ well; New England Nuclear, Boston, MA.) during final $6 \mathrm{hr}$ of culture and then harvested. In other experiments on the twelfth day of culture, the cells were washed, resuspended in RPMI/HI-FBS, and their cytotoxic reactivities were assessed against target $\mathrm{K} 562$.

Assay for cytotoxic activity

K562 cells, a myeloid cell line $\mathrm{e}^{13)}$, were labeled with $\mathrm{Na}_{2}{ }^{51} \mathrm{CrO}_{4}$ (Daiichi Radio Isotope Labs., Ltd., Tokyo) as previously described ${ }^{14)}$ and used as targets. Briefly, cells were combined in a total volume of $1 \mathrm{ml}$ of RPMI/HI-FBS in plastic tubes (Falcon 2058). The tubes were centrifuged at $80 \times \mathrm{G}$ for $5 \mathrm{~min}$ and then incubated for $4 \mathrm{hr}$. After incubation, the tubes were recentrifuged at $800 \times \mathrm{G}$ for $5 \mathrm{~min}$ and $0.5 \mathrm{ml}$ portion of the supernatants was removed and assayed for the percentage of released radioactivity. The percent of specific lysis was calculated as follows.

$\%$ specific lysis $=\frac{\begin{array}{c}\text { Experimental } \mathrm{cpm}- \\ \text { Control } \mathrm{cpm}\end{array}}{\text { Total } \mathrm{cpm}} \times 100$

Where experimental $\mathrm{cpm}$ is the mean value released in the presence of effector cells, control's is that released from target cells incubated with the medium alone, and the total $\mathrm{cpm}$ is the total amount of ${ }^{51} \mathrm{Cr}$ incorporated into target cells. The value for control's released by target alone ranged from 5 to $10 \%$.

PHA response of PBL

Two-tenths milliliters of PBL $\left(5 \times 10^{5}\right.$ cells/ $\mathrm{ml}$ in RPMI/HI-FBS) in each well of a microtest culture plate (Falcon 3072) was cultured in the presence of $10 \mu \mathrm{g} / \mathrm{ml}$ PHA for $72 \mathrm{hr}$. The cells were pulsed with ${ }^{3} \mathrm{H}$-thymidine $(0.5 \mu \mathrm{Ci} /$ well $)$ during final $6 \mathrm{hr}$ of culture and then harvested. Statistical analysis 
Data (mean \pm S.D.) were compared for statistical significance by means of Student's $t$-test and considered as significant if $\mathrm{p}<0.05$.

\section{RESULTS}

PHA response of PBL from young and aged donors

Thymidine incorporation by PBL from eleven young and twelve aged subjects incubated with PHA for $72 \mathrm{hr}$ was measured. As had been previously found, thymidine incorporation was significantly less by aged PBL when compared with that of young PBL (Table 1).

Donor

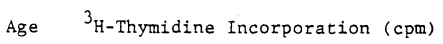

\begin{tabular}{llr}
\hline Young Adult $(\mathrm{n}=11)$ & $27 \pm 3$ & $106138 \pm 30023$ \\
Aged $(\mathrm{n}=12)$ & $78 \pm 5$ & $51355 \pm 21848$
\end{tabular}

Table 1. PHA response of PBL from young and aged donors

\begin{tabular}{llllll}
\hline & \multicolumn{4}{c}{ Number of Cells $\left(1 \times 10^{5} / \mathrm{m} 1\right)$} \\
\cline { 2 - 5 } Donors & \multicolumn{3}{c}{ Days of Culture } & Cumulative Ce11 \\
\cline { 2 - 6 } & $3-6$ & $6-9$ & $9-12$ & $12-15$ & Number $(3-15)$ \\
\hline
\end{tabular}

\begin{tabular}{rrrrrr}
\hline \multicolumn{1}{l}{$\begin{array}{l}\text { Young Adult } \\
1(21)\end{array}$} & 5.3 & 2.0 & 2.5 & 2.5 & 66.3 \\
$2(23)$ & 9.3 & 1.5 & 3.3 & 1.8 & 82.9 \\
$3(24)$ & 7.2 & 6.2 & 3.8 & 2.2 & 373.2 \\
$4(25)$ & 3.0 & 8.2 & 9.7 & 2.2 & 525.0 \\
$5(25)$ & 6.6 & 6.7 & 4.0 & 3.9 & 689.8 \\
$6(26)$ & 2.8 & 4.2 & 3.5 & 1.4 & 57.6 \\
$7(27)$ & 3.0 & 1.9 & 1.9 & 1.3 & 14.1 \\
$8(28)$ & 12.0 & 2.2 & 4.4 & 1.8 & 209.1 \\
$9(31)$ & 4.8 & 7.8 & 5.7 & 3.8 & 811.0 \\
$10(31)$ & 5.5 & 4.3 & 2.1 & 2.5 & 124.2 \\
$11(31)$ & 3.0 & 3.7 & 1.3 & 1.2 & 17.3 \\
Mean (27) & 5.7 & 4.4 & 3.8 & 2.2 & 270.0 \\
Aged & & & & & \\
$1(71)$ & 8.2 & 4.1 & 3.1 & 1.1 & 114.6 \\
$2(72)$ & 6.7 & 4.2 & 3.2 & 2.5 & 225.1 \\
$3(73)$ & 3.6 & 3.1 & 3.0 & 2.7 & 90.4 \\
$4(73)$ & 6.7 & 8.0 & 4.6 & 2.2 & 542.4 \\
$5(75)$ & 4.0 & 9.0 & 1.4 & 2.4 & 121.0 \\
$6(77)$ & 3.8 & 7.0 & 2.5 & 3.4 & 226.1 \\
$7(78)$ & 6.6 & 4.1 & 5.9 & 3.6 & 574.8 \\
$8(79)$ & 2.1 & 2.0 & 2.3 & 1.3 & 12.6 \\
$9(80)$ & 5.3 & 4.5 & 2.8 & 0.9 & 60.1 \\
$10(81)$ & 6.0 & 6.3 & 1.9 & 3.7 & 265.7 \\
$11(83)$ & 3.0 & 2.7 & 3.3 & 2.0 & 53.5 \\
$12(90)$ & 4.0 & 2.5 & 1.1 & 1.5 & 16.5 \\
Mean (78) & 5.0 & 4.8 & 2.9 & 2.3 & 191.9 \\
\hline & & & & & \\
\hline
\end{tabular}

Table 2. Expansion of PBL from young and aged donors with IL-2
Expansion of PBL from young and aged donors with IL-2

The proliferative abilities of PBL from young and aged subjects in IL-2 were shown in Table 2. After incubation with PHA and IL-2 for 2 days, the cells were washed and subcultured every three days at $1 \times 10^{5}$ cells $/ \mathrm{ml}$ with a change of fresh Click's medium containing IL-2. After PHA stimulation, PBL of both young and aged subjects can respond to exogenous lectin-free IL-2 and propagate to a large number in the presence of IL-2. No significant difference was found for the growth capacity between aged and young CLC-IL-2 in each subculture. The growth capacity varied among the individual culture. About $82 \%$ of cultures originated with young PBL expanded to 58- to 811-fold (mean for all young subjects, $270 \pm 273$-fold increase), whereas $83 \%$ of the cultures from aged PBL showed similar growth capacity (mean for all aged subjects, $192 \pm 182$ fold increase) over a period of 3-15 days. Two out of eleven (18\%) from young subjects and $2 / 12$ of the cultures from aged subjects failed to expand to 20 -fold. There was no direct correlation between the growth capacity of the individual cultures and their cytotoxic reactivity (see below). In other experiments, proliferative ability of PBL in IL-2 was evaluated by the method of thymidine incorporation (Table 3). On the ninth and fifteenth day of culture, the cells were pulsed with thymidine in the presence of IL-2. No significant difference in thymidine uptake in response to IL-2 was observed between young and aged CLCIL-2 on the ninth day and on the fifteenth day of culture, respectively.

Cytotoxic reactivity of PBL and CLC-IL-2 of young and aged donors

Cytotoxic reactivity was assessed against the

\begin{tabular}{|c|c|c|c|}
\hline \multirow{2}{*}{ Donor } & \multirow{2}{*}{ Age } & \multicolumn{2}{|c|}{${ }^{3} \mathrm{H}$-Thymidine Incorporation (cpm) } \\
\hline & & Day 9 & Day 15 \\
\hline Young Adult $(n=12)$ & $28 \pm 3$ & $70432 \pm 29390$ & $57334 \pm 26149$ \\
\hline Aged $(n=14)$ & $76 \pm 5$ & $66830 \pm 36413$ & $48589 \pm 27617$ \\
\hline
\end{tabular}

Table 3. ${ }^{3} \mathrm{H}$-Thymidine incorporation by CLC-IL-2 from young or aged donors in response to IL-2 
NK-sensitive target cell K562. The cytotoxic reactivity of fresh PBL in the aged group was $30.5 \pm 7.7 \%$, which did not differ from that in the young group $(29 \pm 9.8 \%)$. CLC-IL-2 derived from the aged and the young groups showed strong cytotoxic reactivity $(75.9 \pm 3.5$ and 77.3 $\pm 3.2 \%$, respectively). No significant difference was found between both groups (Table 4).

\begin{tabular}{llcc}
\hline & & \multicolumn{2}{c}{ Cytotoxicity (\%) } \\
\cline { 3 - 4 } Donor & Age & PBL & CLC-IL-2 \\
\hline Young Adult $(n=11)$ & $27 \pm 3$ & $29.8 \pm 9.8$ & $77.3 \pm 3.2$ \\
Aged $(n=12)$ & $78 \pm 5$ & $30.5 \pm 7.7$ & $75.9 \pm 3.5$ \\
\hline
\end{tabular}

Table 4. Cytotoxic activity of PBL and CLC-IL-2 from young or aged donors against K562 targets

\section{DISCUSSION}

In the present study, we demonstrated that PBL from aged subjects were able to propagate to a large number with supplementation of IL-2. A decrease in lymphocyte responses of the aged humans and animals to $T$ cell mitogens had been reported by several investigators ${ }^{1,2,15,16)}$. The decreased response of PBL from aged subjects to PHA were observed in the present study and also in our previous study ${ }^{14)}$. Gillis et al. ${ }^{15)}$ pointed out that the impaired lymphocyte response to mitogens by aged human is due to defects in both the production and recognition of IL-2. They demonstrated that PBL from aged subjects showed either no change or even a decrease of thymidine incorporation by culture in the presence of PHA and IL-2 when compared with the case of culture in the presence of PHA alone. However, they did not investigate the number of propagated cells due to supplementation of IL-2 after PHA stimulation. Thoman et al. ${ }^{17)}$ reported that spleen cells from old mouse produce less IL-2 in response to mitogenic stimuli but respond to exogenous IL-2. The results we obtained demonstrated that, after PHA stimulation, PBL from aged humans can respond to exogenous $\mathrm{IL}-2$ as those from the young and proliferate to a large number by culture. Thymidine incorporations on the ninth and fifteenth day respectively, showed no difference of proliferative abilities exerted by IL-2, between the young and aged subjects. Therefore, we considered that following interaction of PBL from aged subject with PHA stimulation, a receptor for IL-2 in PBL was expressed and PBL was induced to proliferate to CLC-IL-2 in the presence of exogenous IL-2 as those PBL from young subjects. There is no significant difference being found as their property among IL-2 receptor expressing cells between the young and aged subjects. On the other hand, it is worth noting that a small portion $(18 \%)$ of the eleven young PBL cultures showed a relatively poor growth in the presence of IL-2. The apparent difference between mitogen response and proliferative ability with IL-2 is required to be performed.

Only few on age-associated change of the lymphocyte-mediated cytotoxic reactivity in humans is known. Our previous report ${ }^{14)}$ and those of others ${ }^{18,19)}$ demonstrated that aged healthy subjects have similar normal cytotoxic reactivity against the NK-sensitive target cell K562 when compared with young controls.

The ability of human CLC-IL-2 to lyse the fresh autologous and allogeneic tumor cells in vitro has been reported by some authors ${ }^{5,6)}$. Kedar et $a l^{5)}$ revealed that CLC-IL-2 are in high cytotoxic to K562 targets and also to various tumor cells without prior specific antigen stimulation. In the present study, we demonstrated that CLCIL-2 exhibited a strong cytotoxic reactivity against $\mathrm{K} 562$ targets. In addition to this finding, CLC-IL-2 derived from aged PBL also showed similar potent cytotoxic reactivity against K562 as young controls.

The properties of the present NK-like cytotoxic cells grown under this culturing condition have not been fully defined. Kedar et $a l .{ }^{5)}$ reported that the cytotoxicity shown by CLC-IL-2 is attributable to propagation of NK cells. Sugamura et al. ${ }^{7)}$ also revealed that human NK cells could be proliferated in the presence of IL-2, and cloned T cell lines thus obtained are able to possess NK activity. On the basis of our findings, NK-like activity of the present CLC-IL-2 was significantly diminished by treating with anti-leu 7 (monoclonal antibody to human $\mathrm{NK}$ cell antigens) and complements 
(unpublished data). Human NK cells have been shown to express certain $\mathrm{T}$ cell antigens ${ }^{20)}$. Therefore, we considered that after PHA stimulation, human endogenous NK cells or their precursor cells could proliferate in vitro in the presence of IL-2. However, it is still not elucidated that whether the present NK-like cells being able to grow in IL-2 are identical to those NK cells occurring endogenously in peripheral blood, or not.

Judging from the findings obtained by the present authors, the immunity of aged subjects may be recovered by exogenous IL- 2 and that is according to the reactivity to exogenous IL-2 being possessed by PBL from aged subjects as those PBL from young subjects.

ACKNOWLEDGEMENTS: This work was supported by a grant from the Ministry of Education, Science and Culture (58770551).

\section{REFERENCES}

1) Makinodan T, Adher WH: Effects of aging on the differentiation and proliferation potentials of cells of the immune system. Fed Proc 34: 153, 1975.

2) Weksler ME, Hütteroth TH: Impaired lymphocyte function in aged humans. J Clin Invest 53: 99, 1974.

3) Gillis S, Baker PE, Ruscetti FW, et al: Long-term culture of human antigen-specific cytotoxic $\mathrm{T}$ cell lines. J Exp Med 148: 1093, 1978.

4) Smith KA, Gillis S, Baker PE, et al: T-cell growth factor-mediated T-cell proliferation. Ann N Y Acad Sci 332: 423, 1979.

5) Kedar E, Ikejiri BL, Timonen $T$, et al: Antitumor reactivity in vitro and in vivo of lymphocytes from normal donors and cancer patients propagated in culture with $\mathrm{T}$ cell growth factor (TCGF). Eur J Cancer Clin Oncol 19: 757, 1983.

6) Lotze MT, Grimm EA, Mazumder A, et al: Lysis of fresh and cultured autologus tumor by human lymphocytes cultured in T-cell growth factor. Cancer Res 41: 4420, 1981.

7) Sugamura K, Tanaka Y, Hinuma Y: Two distinct human cloned $\mathrm{T}$ cell lines that exhibity natural killer-like and anti-human effector activities. J Immunol 128: 1749, 1982.

8) Click RE, Benck L, Alter BJ: Immune responses in vitro. I. Culture conditions for antibody synthesis. Cell Immunol 3: 264, 1972.

9) Böyum A: Isolation of mononuclear cells and granulocytes from human blood. Isolation of mononuclear cells by one centrifugation, and granulocytes by combing centrifugation and sedimentation at $1 \mathrm{~g}$. Scand J Clin Lab Invest 21 (Supple 97): 77, 1968.

10) Suzuki H, Yamashita N, Sugiyama E, et al: Role of monocytes in the augmentation of human natural killer cell activity by interleukin-2. Anticancer Res 4: 63, 1984.

11) Gillis S, Ferum MM, Ou W, et al: $T$ cell growth factor: parameters of production and a quantitative microassay for activity. J Immunol 120: 2027, 1978.

12) Okada M, Yoshimura N, Kaieda T, et al: Establishment and characterization of human $\mathrm{T}$ hybrid cells secreting immunoregulatory molecules. Proc Natl Acad Sci USA 78: 7717, 1981.

13) Lozzio CB, Lozzio BB: Human chronic myelogenous leukemia cell-line with positive Philadelphic chromosome. Blood 45: 321, 1975.

14) Sugiyama E, Ito $M$, Suzuki $H$, et al: Natural killer cell activity associated with aging and sex in humans. Jap J Med 22: 195, 1983.

15) Gillis S, Kozak R, Durante M, et al: Immunological studies of aging. Decreased production of and response to $\mathrm{T}$ cell growth factor by lymphocytes from aged humans. J Clin Invest 67: 937, 1981.

16) Hefton JM, Darlington GJ, Casazza BA, et al: Immunologic studies of aging. V. Impaired proliferation of PHA responsive human lymphocytes in culture. J Immunol 125: 1007, 1980.

17) Thoman ML, Weigle WO: Cell-mediated immunity in aged mice: an underlying lesion in IL 2 synthesis. J Immunol 128: 2358, 1982.

18) Marcano NB, Rivas A, Figarella EF, et al: Cellmediated effector mechanisms in aging humans. Int Archs Allergy Appl Immunol 69: 7, 1982.

19) Pross HF, Baines MG: Studies of human natural killer cells. I. In vivo parameters affecting normal cytotoxic function. Int J Cancer 29: 383, 1982.

20) Kaplan J, Callewaert DM: Expression of human Tlymphocyte antigens by natural killer cells. J Natl Cancer Inst 60: 961, 1978. 